\title{
Critique and Theory in the History of the Modern Humanities
}

\author{
Paul Jay \\ Loyola University Chicago, pjay@luc.edu
}

Follow this and additional works at: https://ecommons.luc.edu/english_facpubs

Part of the English Language and Literature Commons

\section{Recommended Citation}

Jay, Paul. Critique and Theory in the History of the Modern Humanities. The Making of the Humanities, III, : 655-665, 2014. Retrieved from Loyola eCommons, English: Faculty Publications and Other Works,

This Book Chapter is brought to you for free and open access by the Faculty Publications and Other Works by Department at Loyola eCommons. It has been accepted for inclusion in English: Faculty Publications and Other Works by an authorized administrator of Loyola eCommons. For more information, please contact ecommons@luc.edu.

\section{(c) (†) $\ominus$}

This work is licensed under a Creative Commons Attribution-Noncommercial-No Derivative Works 3.0 License. (C) Amsterdam University Press, 2014 


\title{
I2.2 Critique and Theory in the History of the Modern Humanities
}

\author{
Paul Jay
}

What role has poststructuralist literary, critical, and cultural theory played in the making of the humanities, particularly in the period between 1968 and the present, and what role should theory have going forward as we come to terms with the corporatization of higher education, with its stress on practical skills, vocational training, and on measuring concrete learning outcomes? Exploring these questions requires confronting - and linking - two key issues currently at the core of sometimes-fierce debates about the humanities in the West, and particularly in the US.

The first issue has to do with whether or not theory since 1968 has served to undermine the traditional coherence of a humanities education, and the second has to do with how humanists and their supporters respond to assertions the humanities have little value because they do not teach students practical skills. In the US in particular these two issues have gotten intertwined.

I will be arguing that since theory has always been central to the humanities it is a mistake to argue it has somehow undermined and marginalized them. This is especially the case at a time when questions are being raised about the practical skills humanities students acquire, for the skill of critical thinking is at the very heart of an education in theory. Claims that a humanities education has no practical utility are surprisingly common. Indeed, such a claim is often worn as a badge of prestige by humanists themselves. For example, the well-known literary critic and New York Times columnist Stanley Fish has insisted that the humanities

don't do anything, if by 'do' is meant bring about effects in the world. And if they don't bring about effects in the world they cannot be justified except in relation to the pleasure they give to those who enjoy them. To the question 'of what use are the humanities?', the only honest answer is none whatsoever.' 
And Frank Donoghue, writing about the marginalization of the humanities in an increasingly vocation-centered university, surrenders to a dangerous fatalism. 'Curricula change overtime', he notes, 'and the humanities simply don't have a place in the emergent curriculum of the twenty-first century.' With friends like this the humanities do not need any enemies.

The failure to rise to the challenge of defending the humanities in terms of the practical skills they teach is all too often a retreat into idealism. Worse still, it usually comes off as defeatist. It avoids the necessity of developing a pragmatic position in the face of realities that are not going to go away. Arguing that the humanities have gotten sidetracked by abstract, esoteric theories fails to recognize that theory is intimately related to critique, that critique has been at the center of debates about humanism since its inception, and that critique is demonstrably connected to the practical skill we sometimes too loosely call 'critical thinking'. For this reason, highlighting the role of theory as critique in the humanities is one of the best ways to highlight the practical utility of a humanities education.

\section{Critical Theory and the end/ends of the humanities}

Observers who complain theory has ruined the humanities argue that from 1850 to about 1968 the humanities developed a curricular and intellectual coherence that was successively undermined by structuralist, deconstructive, psychoanalytic, queer and Marxist theory, and later by multiculturalism, feminism, and the rise of postcolonial and cultural studies. ${ }^{3}$ This old coherence was based largely on an attitude of deference to canonical texts and traditional humanist ideals. It was connected to what the American critic Andrew Delbanco has called a curatorial model of scholarship and teaching. ${ }^{4}$ According to this narrative, the primary role of the humanities was to preserve and explore a great tradition of humanist work in literature, philosophy, the fine arts, history, and religion, encouraging students, following Matthew Arnold's ideal, to study with disinterest the best that has been thought and written.

The problem with theory, from Delbanco's perspective, is that it abandoned deference and disinterest in favor of criticism, fracturing a coherence organized around great books and the ostensible pursuit of 'universal truths' at the core of Western humanism. The complaint about theory from this perspective is that its focus on difference and diversity turned our attention away from what unites us to what divides us. According to this narrative, difference replaced universality as the key principle directing the pursuit of knowledge in the humanities. Following this new model, the humanities turned its attention to analyzing the exclusion 
of differences as a constitutive move in the construction of the very notion of a 'common humanity', and this attention led to an explosion of work across the disciplines of the humanities on the importance of particular differences related to things like culture, gender, race, and sexual orientation. It also led to what traditional humanists came to feel was a counterproductive critique of humanism itself, one that undermined the very notion of a humanities education.

Of course traditional humanists were hardly wrong in seeing theory as a threat to humanism, for theorists as varied as Michel Foucault, Jacques Derrida, and Louis Althusser (along with French feminists such as Monique Wittig, Luce Irigaray, and Hélène Cixous) often presented their work as announcing the end of humanist man. While humanism tended to see the human subject as a sovereign agent, language as a transparent medium for that agency, and truth as the product of a reason that transcended history, these theorists and their followers questioned the autonomy and agency of the subject, the transparency of language, the foundations of reason, and the whole idea that truth could stand outside history and culture as universal and foundational. The most oft-cited version of this idea is Foucault's declaration near the end of The Order of Things that 'man is neither the oldest nor the most constant problem that has been posed for human knowledge', that 'one can be certain that man is a recent invention [...] and one perhaps nearing its end.' Derrida's critique of metaphysics, the questions he raises about the idea of presence, and his criticism of the equation between voice, reason, and the subject, was also framed as a frankly anti- or posthumanist approach to subjectivity. And the work of both Derrida and Foucault is consistent with that of Althusser, who insisted on the fundamentally anti-humanist orientation of Marxism and argued that the putatively autonomous humanist subject was a product of ideology and language, a being not sovereign but interpellated. From this point of view, theory's critique of humanism seemed to betray the very ideals upon which the humanities were built. ${ }^{6}$ Why? Because theory substituted ideological critique for disinterest, made it more difficult to explore our common humanity, and seemed to fracture the curricular coherence of a humanities education by marginalizing the great works of the Western tradition in favor of inferior texts by formerly marginalized writers.

While there is no denying how dramatically poststructuralist theory has transformed the humanities, it is by no means necessary to see theory as anti-humanist. Indeed, as Martin Halliwell and Andrew Mously have shown, ${ }^{7}$ humanist thought is too diverse a tradition to be reduced to a single line of thinking about human subjectivity. They question the standard narrative that contemporary critical theory constituted a 'complete rupture' with humanism. Instead, they argue that the work of thinkers like Baudrillard, Derrida, Foucault, Kristeva, Lacan, and Lyotard, ought to be seen as developing a more nuanced, self-reflexive, and 
'rigorous theory' of the human. From this point of view, contemporary critical theory 'takes the human to be an open-ended and mutable process', but this does not have to be seen as an anti-humanism. A postfoundationalist view of the human', suspicious of essentialist categories, is in their view an 'ethically and politically grounded humanism.'

I think they are right, and that it is important to recognize not simply how contemporary critical theory can be understood as an attempt to productively modify the substance of humanist thinking, but how the kind of critical thinking theory performs is itself central to the tradition of humanism. The danger in dismissing theory as anti-humanist is that it runs the risk of elevating subjects of knowledge (call it cultural literacy) over learning how to think critically about systems of thought, ideologies, and authority (what I would call critical literacy). One of the most significant drawbacks of this position is that it sees objects of knowledge and the practice of critique in either/or terms. This problem is exemplified by Delbanco's distinction between curation and criticism. According to Delbanco, the humanities went astray when criticism overwhelmed curation, when theory and the critique of humanism took the place of the humanities" respon sibility to preserve and venerate a traditional body of knowledge (and the seemingly timeless authority it had). What this point of view misses, of course, is the reciprocal relationship between curation and criticism, for to a significant degree the act of curation requires criticism, and criticism is itself a form of curation.

A curator does not just make decisions based on quality and distinction. $\mathrm{He}$ or she is also critically and imaginatively involved in putting together objects in ways that produce new relations between things and new forms of knowledge. Humanities scholars and educators curate by being critical in this more capacious sense of the term. Contemporary work in the humanities is therefore curatorial in the best sense of the word. It both reorganizes old materials and gathers them together with new materials to create new perspectives on both the past and the present. This means theory is not a threat to the curatorial enterprise, but rather, is central to its intellectual and pedagogical vitality.

Because theoretical thinking has always been central in mainstream humanism, the distinction between preservation and critique simply does not hold up. Delbanco wants the great texts or art works in literature, philosophy, art history, or religious studies to be the primary focus of attention, but in a way that runs the risk of separating them off - even protecting them - from criticism. In his view the act of curation must always take precedence over what he takes to be the counterproductive practices of criticism. My point, of course, is not to argue that Delbanco gets it backwards - that the humanities ought to be all about criticism and that they ought to put curation on the back burner. My point is that the two 
activities are interdependent. When we articulate the value of the humanities we need to emphasize not only the body of knowledge they preserve but also the value of the forms of critique they teach, and to underscore that critique is a practical skill integral to both scholarly work and critical citizenship.

\section{Theory, critique, and the tradition of humanism}

Now, what do I mean when I invoke the word critique, and how has critique been central to the making of the humanities? Let me be clear: by critique I do not simply mean critical thinking. The phrase 'critical thinking' has become a terribly overused catch phrase in discussions of higher education, and it is often very loosely defined - if it is defined at all. By critique I mean the practice of systematically analyzing and interrogating the constitution of conceptual categories and the sources of their authority. Critique explores historically and conceptually the development of norms that regulate our personal, social, and political lives together (for that matter, it explores the historical constitution of the very 'we' these norms are supposed to protect).

It is important to stress here that there is such a thing as critique itself - separable from particular critiques of particular discourses. And critique can be taught, not just particular critiques, but the activity of critique per se. Indeed, this is what we teach when we teach critical theory. Judith Butler, writing about Foucault's conception of critique, has observed that critique

will be dependent on its objects, but its objects will in turn define the very meaning of critique. Further, the primary task of critique is not to evaluate whether its objects - social conditions, practices, forms of knowledge, power, and discourse - are good or bad, valued highly or demeaned, but to bring into relief the very framework of evaluation itself. ${ }^{9}$

This meta-level in critique, this bringing into relief the very framework of evaluation itself' is at the heart of the activity we call critique.

Critique is, in this sense, at the very heart of the humanist enterprise. It involves the kind of abstract, systematic thinking we associate with Kant's theory of the aesthetic, Hegel's dialectic, Marx's analysis of the class structure or the operations of ideology, Nietzsche's idea of the death of god, or Freud's work on the unconscious, or his great work, Civilization and Its Discontents. But it also involves our evaluating the very frameworks of evaluation that have been employed to think about those critiques, including our own evaluation of those evaluations. Indeed, it is quite impossible to think about humanism, and thus the humani- 
ties, without thinking of the primary role that dissent and critique played in the development of Enlightenment thought, especially in terms of its radical proposals about human liberty and agency, about the primacy and autonomy of the individual, and about the natural or human rights everyone is entitled to. All of these ideas involved a theoretical critique of the status quo. It was what humanism, at its very foundations, was all about. From this point of view, the criticism of theory's place in the humanities makes no sense. Worse still, it seems to strike at the very heart of the humanist enterprise, relegating its critical vitality to the past. Seen this way, humanism is over, fixed, curated, and sanitized. It is worthy of historical study, but not something that still lives.

One thing that is particularly interesting about Butler's discussion of Foucault's approach to critique is her focus on how he associates critique with virtue, the cultivation of which - along with an ethical sensibility - we like to associate with a humanities education. About his idea that there is something in critique that is akin to virtue' Foucault observes, ${ }^{10}$

virtue is most often understood either as an attribute or a practice of a subject, or indeed a quality that conditions and characterizes a certain kind of action or practice. It belongs to an ethics which is not fulfilled merely by following objectively formulated rules or laws. And virtue is not only a way of complying with or conforming with pre-established norms. It is, more radically, a critical relation to those norms."

This critical relation to norms, Butler emphasizes, involves'a resistance to authority', something Butler points out Foucault saw as absolutely central to Enlightenment critiques of the status quo.

Although Butler is quick to point out that most Enlightenment thinkers would not understand the link between critique and virtue in this kind of way, she insists that 'this resistance would not invalidate' the link Foucault makes, for what he seeks in the characterization of the Enlightenment is precisely what remains "unthought" within its own terms: hence, his is a critical history' of critique. ${ }^{12}$ 'In his view', she concludes, 'critique begins with questioning the demand for absolute obedience and subjecting every governmental obligation imposed on subjects to a rational and reflective evaluation. ${ }^{13}$ Foucault's connection between virtue and critique, of course, is aimed precisely at exposing these operations and therefore has the potential to be liberatory.

Linking theory to critique, and considering its liberatory potential in the way I have been sketching out, underscores a key problem with conservative criticisms of theory. On the one hand, the popular idea that theory has ruined the humanities is often based on the quite accurate idea that theory has had a lot of critical 
things to say about humanism. But on the other hand, that argument misses the fact that theory's critique of humanism is thoroughly consistent with the centrality and purpose of critique in humanism itself, and that its purpose, by and large, has been to ensure the ideals of liberty and agency at the heart of humanism are extended to everyone. For this reason, contemporary theory - contemporary critique - ought not to be thought of as anti- or posthumanist, although as we have seen above, some theorists like to style it that way. In my view, such terms are quite counterproductive. In an age when the humanities are imperiled, it makes little sense to use the rhetoric of anti- or posthumanism in articulating its value. There is no reason why theory and its critique of humanism cannot be folded into a positive articulation of a twenty-first-century humanism.

Instead of seeing theory as a threat to humanism, new ways of thinking about the human subject, the role that language plays in constructing reality and shaping meaning and value, and how gender, sexual orientation, race, ethnicity, and class both shape identity and enable or circumscribe agency, ought to be seen as constructively rethinking and expanding traditional humanist claims about individuality, autonomy, liberty, and rights. In my view, contemporary forms of humanistic critique are, by and large, interested in helping to broaden, and diversify these claims, to make the discourse of humanism more, not less legitimate. Although in its most radical moments, theory seemed to be announcing the end of man or the beginning of a posthumanist age, it has actually represented constructive, forward-looking dissent from the historical limits of humanism, dissent that sought to expand, correct, and broaden humanist ideals.

Examples abound. Although, as we have seen, Foucault's remarks about the 'end of man' have often been cited as an example of the anti-humanist orientation of contemporary theory, it makes more sense to see his work on the relationship between subjectivity, discourse, ideology, and power - along with theory's general critique of the idealist human subject of eighteenth- and nineteenth-century philosophy - as a contribution to refining and clarifying our humanist understanding of subjectivity and agency. From this point of view, contemporary theory is all about insuring that the humanist guarantee of agency and rights is extended to everyone, not just the traditional human subject of universal man'.

Here, of course, feminist theory becomes another, crucial example of a critical theory that, while it might be presented as anti-humanist, is anything but. On the one hand, feminism dissents from humanism's notion of 'man', based as it is on the universalizing of a version of human nature derived by, and largely based on, male experience, but on the other hand feminism is linked to humanism in its insistence that women be accorded the same set of rights and the same kind of autonomy and agency associated with traditional humanism. On the critical side, of course, feminist theory and history help foreground the patriarchal orientation of 
humanism. Not simply in the trivial and quite obvious sense that virtually all of the early thinkers and writers associated with humanism were males whose status as scholars and educators was predicated on all of the privileges that came with being male in a patriarchal system, privileges that were unavailable to women (who, more often than not, were treated as the property of men). The less obvious but perhaps even more important point is that the identity category of gender is altogether absent inside humanist thinking about the human. We should not see this simply as linguistic hair splitting, believing that the great writers of Renaissance, Enlightenment, or modern humanism meant to include women when they wrote 'man'. Too often they did not. Humanist 'man' was conceptualized from the experience of male human beings; it is about forms of power, thought, agency and autonomy (not to mention access to education and therefore to the very activity of scholarship upon which humanism is founded) historically only accessible to men.

However, as critical as feminism is of how humanism's philosophy of man kept women disenfranchized, it is important to see contemporary feminist theory as part of a struggle to expand humanism's ideals with regard to individual autonomy and liberty rather than as an attempt do away with humanist ideals altogether. Like Marxism, feminism has had a double relationship to humanism, simultaneously launching a critical dissent from, and insisting on the broad legitimating and application of, its central ideals about human individuality, autonomy, and agency. This kind of work, while often cast as post-or anti-humanist, ought to be understood as part of an evolving discourse within humanism about what it means to be human, and about what ought to be included in a humanities education. It constitutes both a dissent from humanism, and an extension of its logic.

\section{Theory, critique, and critical thinking}

Linking theory to critique, and critique to critical thinking, not only makes intellectual and historical sense. It makes strategic sense as well. Critical thinking is routinely cited as the single most important practical skill the humanities teach, yet, as I indicated earlier, it is often invoked with little attempt to define it. Many of the same people who are critical of the role of theory in the humanities are the same people who emphasize the importance of critical thinking, which means they are missing the fact that critical theory courses are some of the best courses in critical thinking we have in higher education. Seeing critical theory as training in critical thinking emphasizes the general utility of such courses, but it also helps add substance to a concept that is often invoked but rarely defined in discussions about higher education. For example, The Foundation for Critical Thinking outlines an approach to critical thinking that links it to the kind of theoretical think- 
ing associated with structuralism, deconstruction, and other social, cultural, and political theories that challenge received dogmas and entrenched assumptions. ${ }^{14}$ For example, the foundation's mission statement declares that critical thinking cultivates 'intellectual discipline [...] self-reflection and open-mindedness', insisting that it requires a break with 'automation and fixed procedure' and embraces 'radically different' forms of 'thinking [...] adaptable, more sensitive to divergent points of view'. And critical thinking is also tied explicitly to social changes under globalization.

The world in which we now live requires that we continually relearn, that we routinely rethink our decisions, that we regularly reevaluate the way we work and live. In short, there is a new world facing us, one in which the power [...] to regularly engage in self-analysis, will increasingly determine the quality of our work, the quality of our lives, and perhaps even our very survival.

This approach to critical thinking underscores its foundations in theoretical thinking and critique in disciplines across the humanities, but also to challenging, resisting, and rethinking those forms in the very act of using them. From this point of view you cannot have critical thinking without theory, for what's being subjected to critical thinking here are entrenched, naturalized professionalized assumptions and protocols. Critical thinking involves asking challenging questions about ways of thinking and conceptualizing problems that have become automatic and fixed. This approach to critical thinking, which deals with received concepts openmindedly within alternative systems of thought, recognizing and assessing, as need be, their assumptions, implications, and practical consequences', is strikingly in sync with the shorthand definition of theory Jonathan Culler provides. 'The main effect of theory', he points out, 'is the disputing of 'common sense': common-sense views about meaning, writing, literature, experience. ${ }^{15}$ Theory, from this perspective, is a form of critical thinking that in challenging old, naturalized orthodoxies gets us to see that what we take to be 'common sense' explanations and assumptions are in fact theories. For 'theory', Culler explains, is an attempt to show that what we take for granted as "common sense" is in fact a historical construction, reflecting a particular theory that has come to seem so natural to us that we don't even see it as a theory.'. ${ }^{16}$

Theory in the humanities, then, is not a distraction from what the humanities ought to be doing. Theory is central to what everyone believes the humanities ought to be doing: teaching critical thinking. It is a way of thinking critically about humanism and the gap between what it advocates and who has benefited from what it advocates. And theory challenges students to think open-mindedly 
in the context of divergent points of view about their core beliefs, to rethink and reevaluate their positions, and to entertain radically different forms of thinking about how meaning is produced, about the relationship between art, philosophy and power, and about the relationship between class, gender, race, sexual orientation, and social justice. From this point of view theory, as it challenges traditionally entrenched ways of doing intellectual and historical business, is an important vehicle for critical thinking and is thus central to the core mission of the humanities. Indeed, it is one of the most concrete examples we have of teaching critical thinking.

\section{Conclusion}

To come back to the double argument I have been making, all of this means not only that theory ought not to be seen as a distraction from what the humanities should be doing, but even more importantly, that theory ought to be seen as central to both the history of humanism and the range of practical skills we teach in the humanities. We should not allow theory to become the scapegoat for what critics believe is wrong with the humanities. Indeed, we need to go beyond defending theory and actively argue for its centrality in the traditions of humanism we teach, and the contemporary humanities we increasingly have to defend.

\section{Notes}

I Stanley Fish, 'Will the Humanities Save Us?' The New York Times, January 6, 2008, URL: http://opinionator.blogs.nytimes.com/? $\mathrm{s}=$ will+the+humanities +save+us.

2 Frank Donoghue, 'Will the Humanities Survive the 2ist Century?', The Chronicle of Higher Education, September 5, 2010.

3 Leaders of the attack on theory at the height of the so-called culture wars in the US included William Bennett, Lynn V. Cheney, Dinesh D'Souza, and Roger Kimball, among others. For an interesting discussion of why they got it wrong, see Mark Bauerlein, 'The Attack on Theory', The Chronicle of Higher Education, February 9, 2013. URL: http:// chronicle.com/blogs/brainstorm/the-attack-on-theory/6135.

4 Andrew Delbanco,'A New Day for Intellectuals', February 1 3, 2009. URL: http://chronicle.com/article/A-New-Day-for-Intellectuals/21359.

5 Michel Foucault, The Order of Things: An Archaeology of the Human Sciences (New York, Vintage Books, 1994), 386-387.

6 This was, of course, the main thrust of conservative critiques in the United Sates of contemporary theory produced by people like William Bennett, Lynn Cheney, and Dinesh D'Souza.

7 Martin Halliwell and Andy Mousley, Critical Humanisms: Humanist/Anti-Humanist Dialogues (Edinburgh: Edinburgh University Press, 2003). 
8 Halliwell and Mousley, Critical Humanisms, $\mathrm{I}-2$.

9 Judith Butler, 'What Is Critique? An Essay on Foucault's Virtue', in eipcp, a publication of the European Institute for Progressive Policies, May, 2001. URL: http://eipcp.net/ transversal/0806/butler/en.

Io Quoted in Butler, 'What Is Critique?'

II Ibid.

I2 Ibid.

I3 Ibid.

I4 URL: http://www.criticalthinking.org.

15 Jonathan Culler, Literary Theory: A Very Short Introduction (New York: Oxford University Press, 20II), 4.

I6 Culler, Literary Theory, 4 . 